\title{
EDITORIAL
}

\section{Patient-centred asthma education in the emergency department: the case in favour}

\author{
M.R. Partridge
}

n n many countries of the world, despite an increase in the prevalence of asthma, there has been a reassuring recent decline in mortality and rates of hospitalisation due to the disease. Whilst this may appear to be good, considerable morbidity persists which may be under-recognised by the patient [1] and there is a danger of complacency developing amongst health professionals. If further initiatives to improve care are necessary then it would appear sensible to focus those efforts on areas of maximal need. One such area is the attendance of those with asthma at emergency departments (EDs).

Patients who attend EDs may bypass other healthcare facilities and may be repetitive attendees. In a UK national census half of all those attending EDs were adults, a third had been admitted to hospital in the previous 12 months and a quarter had attended an ED in the previous 3 months [2]. A multicentre French study has emphasised the seriousness of this situation and has shown that $26 \%$ of those attending EDs have life threatening attacks. A further $49 \%$ were classified as having severe exacerbations [3]. As part of an initiative to identify factors associated with repeat ED visits by adults with asthma, one study has demonstrated that, in addition to severity, the lack of self-management education and of possession of a written asthma action plan may increase the likelihood of attendance [4].

As a result of this, other clinicians have called for a more aggressive approach to such patients and suggested the need to improve self-care and bring together patients, physicians and nonphysicians involved in education [5].

Suitable initiatives might include the following. 1) Enhanced educational efforts among all healthcare professionals caring for those with asthma to ensure optimal care, regular followup and appropriate self-management education so that asthma does not deteriorate to the point where attendance in the ED becomes necessary. 2) Rigorous schemes to ensure that those attending the ED are followed up by their primary care physician or by a specialist. 3) Rigorous schemes to ensure that all such patients are referred to an asthma-education programme. 4) Opportunist education within the ED at the time of the patient's attendance.

\section{STATEMENT OF INTEREST: None declared}

CORRESPONDENCE: M.R. Partridge, NHLI Division, Faculty of Medicine, Imperial College London, Charing Cross Campus, St Dunstan's Road, London W6 8RP, UK. Fax: 44 2088467999. E-mail: m.partridge@imperial.ac.uk
Unfortunately the first approach has achieved limited success. National guidelines $>17$ yrs ago recommended that "as far as possible patients should be trained to manage their own treatment rather than be required to consult their doctor before making changes" [6]. However, this process has not been well implemented. Numerous studies and systematic reviews have shown the effectiveness of self-management education, monitoring and follow-up in terms of reduction in symptoms, timeoff work and school, and the need for unscheduled healthcare [7]. Part of this self-management education process is the receipt by patients with asthma of a written asthma action plan personalised to their situation. Other reviews have demonstrated the important actions to be included in such a plan [8]. If we survey the prevalence of patients receiving such a written personal action plan and use that as a marker of the frequency with which self-management education is offered, the results of studies in the UK and elsewhere suggest that this approach to management is poorly implemented [9]. This is likely to be due to an organisational failure rather than an unwillingness of patients to be involved. Patients, including those in minority ethnic groups [10], have been reported to express a wish for greater involvement in treatment decisions [11] and would welcome a written personal action plan [9]. Therefore, other approaches need to be explored.

Other possible interventions may involve efforts to integrate such patients back into review by nonemergency services, or following up ED attendances by specialist review or referral to an educational programme. Patient-reported self-management of exacerbations has been shown to be reduced in those offered three 6-weekly outpatient appointments with a specialist asthma nurse following attendance in a hospital ED [12]. A similar US study confirmed the benefits of such an intervention in terms of reduction in repeat ED attendances, and reported a very healthy cost benefit to the educational programme [13]. Alternatively, after ED attendance, referral could be to the patient's usual primary care physician for follow-up, with the hope that it leads to optimisation of therapy, rather than to a specialist nurse or an education programme. Two different methods of encouraging patients to attend a primary care physician following an ED visit have been assessed and it was found that making the appointment on the patient's behalf increased the likelihood of primary care review but, unfortunately, enhanced primary care follow-up did not alter longterm outcomes [14].

The next logical area of study must be to assess the impact of opportunist education during the attendance of patients with 
out-of-control asthma within the ED. At such a time, distress associated with the exacerbation has to be acknowledged and educational intervention needs to be brief; however, this may be the only opportunity to offer the patient key messages that might lead to subsequent behavioural change. Patient-centred care is currently a subject of considerable interest and is an approach strongly supported by the published literature [15, 16]. A patient-centred style improved parental satisfaction and increased parent and child participation in a study of children with asthma in the ED [17]. If we are to attempt education of patients attending EDs with out-of-control asthma it therefore seems sensible to take the same patient-centred approach. Valuing the patient to the extent that the approach is tailored to what is important to them seems intuitively to be far more likely to lead to success, rather than imposing upon them a set of information which we believe to be important.

Therefore, the approach by SMITH et al. [18], in the current issue of the European Respiratory Journal, is to be welcomed. The work that has gone into that study cannot be underestimated; one researcher educated all patients irrespective of the time of day or night that they attended. Asthma studies of any sort are notoriously difficult in terms of recruitment and retention; SMITH et al. [18] are constrained in their conclusions but correctly say that there is certainly enough evidence to justify a further large, multicentre study and the patient-centred approach to education, which intuitively appears to be correct, looks promising. If further trials confirm the benefit of this approach, thought will need to be given to the logistics involved in delivering such care for $24 \mathrm{~h}, 7$ days a week, and further health-economic analysis will be needed as well as comparison with other types of nurse-led intervention [12].

There is more to good asthma care than a prescription and we have to offer our prescriptions within an appropriately supportive context. This means care at a convenient time for the patient and care that recognises the individual, hears their concerns, addresses those concerns and offers the patient the skills, tools and knowledge that they feel to be necessary to enable them to manage their own condition for the $99 \%$ of their lives when they are not in the presence of a doctor.

\section{REFERENCES}

1 Partridge MR, Molen TV, Myrseth SE, Busse WW. Attitudes and actions of asthma patients on regular maintenance therapy: the INSPIRE study. BMC Pulm Med 2006; 6: 13.

2 Partridge MR, Latouche D, Trako E, Thurston JG. A national census of those attending UK accident and emergency departments with asthma. The UK National Asthma Task Force. J Accid Emerg Med 1997; 14: 16-20.

3 Salmeron S, Liard R, Elkharrat D, Muir J, Neukirch F, Ellrodt A. Asthma severity and adequacy of management in accident and emergency departments in France: a prospective study. Lancet 2001; 358: 629-635.
4 Adams RJ, Smith BJ, Ruffin RE. Factors associated with hospital admissions and repeat emergency department visits for adults with asthma. Thorax 2000; 55: 566-573.

5 Popa V. Emergency department visits in asthma: should all be prevented? Chest 2001; 120: 1058-1061.

6 Guidelines for management of asthma in adults: I Chronic persistent asthma. Statement by the British Thoracic Society, Research Unit of the Royal College of Physicians of London, Kings' Fund Centre, National Asthma Campaign. BMJ 1990; 301: 651-653.

7 Gibson PG, Powell H, Coughlan J, et al. Self-management education and regular practitioner review for adults with asthma. Cochrane Database Syst Rev 2003; 1: CD001117.

8 Gibson PG, Powell H. Written action plans for asthma: an evidence-based review of the key components. Thorax 2004; 59: 94-99.

9 Haughney J, Barnes G, Partridge M, Cleland J. The Living and Breathing Study: a study of patients views of asthma and its treatment. Prim Care Respir J 2004; 13: 28-35.

10 Hussein S, Partridge M. Perceptions of asthma in South Asians and their views on educational materials and selfmanagement plans: a qualitative study. Patient Educ Couns 2002; 48: 189-194.

11 Caress AL, Beaver K, Luker K, Campbell M, Woodcock A. Involvement in treatment decisions: what do adults with asthma want and what do they get? Results of a cross sectional survey. Thorax 2005; 60: 199-205.

12 Levy ML, Robb M, Allen J, Doherty C, Bland JM, Winter RJ. A randomized controlled evaluation of specialist nurse education following accident and emergency department attendance for acute asthma. Respir Med 2000; 94: 900-908.

13 Bolton MB, Tilley BC, Kuder J, Reeves T, Schultz LR. The cost and effectiveness of an education program for adults who have asthma. J Gen Intern Med 1991; 6: 401-407.

14 Baren JM, Boudreaux ED, Brenner BE, et al. Randomized controlled trial of emergency department interventions to improve primary care follow-up for patients with acute asthma. Chest 2006; 129: 257-265.

15 Little P, Everitt H, Williamson I, et al. Preferences of patients for patient centred approach to consultation in primary care: observational study. BMJ 2001; 322: 468-472.

16 Little P, Everitt H, Williamson I, et al. Observational study of effect of patient centredness and positive approach on outcomes of general practice consultations. BMJ 2001; 323: 908-911.

17 Wissow LS, Roter D, Bauman LJ, et al. Patient-provider communication during the emergency department care of children with asthma. The National Cooperative InnerCity Asthma Study, National Institute of Allergy and Infectious Diseases, NIH, Bethesda, MD. Med Care 1998; 36: 1439-1450.

18 Smith S, Mitchell C, Bowler S. Standard versus patientcentred asthma education in the emergency department: a randomised study. Eur Respir J 2008; 31: 990-997. 